\title{
PENINGKATAN KOMPETENSI MAHASISWA MELALUI PROGRAM MERDEKA BELAJAR KAMPUS MERDEKA (MAGANG PRAKTEK KERJA DI PT SANG HYANG SERI (PERSERO) CABANG SIDRAP)
}

\author{
Evi Erviana. N \\ Ilmu Pemerintahan, Fakultas Ilmu Sosial dan Ilmu Politik, Universitas Muhammadiyah Sidenreng \\ Rappang \\ eviervianan@gmail.com
}

\begin{abstract}
ABSTRAK
Proses pembelajaran dalam Kampus Merdeka merupakan salah satu perwujudan pembelajaran yang berpusat pada mahasiswa (student centered learning) yang sangat esensial. Salah satu dari program merdeka belajar adalah Magang praktek kerja. Program magang praktek kerja memberikan pengalaman kepada mahaiswa, karena pembelajaran langsung ditempat kerja. Selain mendapatkan keterampilan, mahasiswa mendapatkan kemampuan problem solving, kemampuan menganalisis, serta soft skill seperti etika bekerja, komunikasi dan bekerja sama. Magang Praktek Kerja yang dilakukan bertempat di PT Sang Hyang Seri Cabang Sidrap. PT Sang Hyang Seri (Persero) bergerak dalam bidang perbenihan pertanian dituntut untuk menyiapkan benih secara tepat untuk memenuhi kebutuhan konsumen (petani) dan laba yang optimal untuk kelangsungan hidup perusahaan.Magang praktek kerja dilaksanakan selama 4 bulan. Sebelum pelepasan mahasiswa kelokasi, mahasiswa terlebih dahulu dibekali melalui pembekalan dengan menjelaskan tujuan dari program MBKM ini. Dengan berbagai kegiatan yang dilakukan, mahasiswa sebagai peserta Magang Praktek Kerja mendapatkan banyak pengalaman baru disini. Selain hardskill, softskill pun didapatkan.Kompetensi mahasiswa meningkat dengan banyaknya pengalaman yang didapatkan selama bermagang di instansi. Selain Hardskill yang didapatkan seperti keterampilan, softskill juga didapatkan seperti etika bekerja. Dengan adanya partisipasi masyarakat akan mendukung pelaksanaan program pembangunan salah satunya yaitu kelompok tani yang tentunya bisa mendukung terwujudnya swasembada.
\end{abstract}

Kata Kunci : Kompetensi, Partisipasi, Kinerja 


\section{PENDAHULUAN}

Perubahan peradaban insan akhirakhir ini berjalan sangat cepat dipacu sang perkembangan teknologi khususnya teknologi informasi, terlebih menggunakan adanya pandemi Covid-19 sebagai akibatnya membutuhkan perubahan konduite insan. Perubahan ini dalam akhirnya berdampak pula terhadap permintaan pasar akan kualitas Sumber Daya Manusia (SDM) pembangunan. Pendidikan Tinggi menjadi pencetak SDM unggul ikut bertanggungjawab pada menyiapkan SDM yg dibutuhkan. Program Merdeka BelajarKampus Merdeka merupakan acara Kementerian Pendidikan \& Kebudayaan yg bertujuan untuk memperkuat kompetensi lulusan, mendorong mahasiswa buat menguasai banyak sekali keilmuan yg bermanfaat buat memasuki global kerja \& menaruh kesempatan bagi mahasiswa buat menentukan mata kuliah yg akan mereka ambil. (Muniarty \& Saputri, 2021)

\section{Dalam rangka menyiapkan} mahasiswa menghadapi perubahan sosial, budaya, dunia kerja dan kemajuan teknologi yang pesat, kompetensi mahasiswa harus disiapkan untuk lebih gayut dengan kebutuhan zaman. Link and match tidak saja dengan dunia industri dan dunia kerja tetapi juga dengan masa depan yang berubah dengan cepat. Perguruan Tinggi dituntut untuk dapat merancang dan melaksanakan proses pembelajaran yang inovatif agar mahasiswa dapat meraih capaian pembelajaran mencakup aspek sikap, pengetahuan, dan keterampilan secara optimal dan selalu relevan.
Berbagai bentuk kegiatan belajar di luar perguruan tinggi, di antaranya melakukan magang/ praktik kerja di Industri atau tempat kerja lainnya, melaksanakan proyek pengabdian kepada masyarakat di desa, mengajar di satuan pendidikan, mengikuti pertukaran mahasiswa, melakukan penelitian, melakukan kegiatan kewirausahaan, membuat studi/ proyek independen, dan mengikuti program kemanusisaan. Semua kegiatan tersebut harus dilaksanakan dengan bimbingan dari dosen. Kampus merdeka diharapkan dapat memberikan pengalaman kontekstual lapangan yang akan meningkatkan kompetensi mahasiswa secara utuh, siap kerja, atau menciptakan lapangan kerja baru.

Proses pembelajaran dalam Kampus Merdeka merupakan salah satu perwujudan pembelajaran yang berpusat pada mahasiswa (student centered learning) yang sangat esensial. Pembelajaran dalam Kampus Merdeka memberikan tantangan dan kesempatan untuk pengembangan inovasi, kreativitas, kapasitas, kepribadian, dan kebutuhan mahasiswa, serta mengembangkan kemandirian dalam mencari dan menemukan pengetahuan melalui kenyataan dan dinamika lapangan seperti persyaratan kemampuan, permasalahan riil, interaksi sosial, kolaborasi, manajemen diri, tuntutan kinerja, target dan pencapaiannya. Melalui program merdeka belajar yang dirancang dan diimplementasikan dengan baik, maka hard dan soft skills mahasiswa akan terbentuk dengan kuat. 
Salah satu dari program merdeka belajar adalah Magang praktek kerja. Program magang praktek kerja memberikan pengalaman kepada mahaiswa, karena pembelajaran langsung ditempat kerja. Selain mendapatkan keterampilan, mahasiswa mendapatkan kemampuan problem solving, kemampuan menganalisis, serta soft skill seperti etika bekerja, komunikasi dan bekerja sama.

Magang Praktek Kerja yang dilakukan bertempat di PT Sang Hyang Seri Cabang Sidrap. PT Sang Hyang Seri (Persero) merupakan Badan Usaha Milik Negara (BUMN) yang bergerak dalam bidang perbenihan pertanian dituntut untuk menyiapkan benih secara tepat untuk memenuhi kebutuhan konsumen (petani) dan laba yang optimal untuk kelangsungan hidup perusahaan. Oleh karena itu, produktivitas pabrik benih dalam memproduksi benih merupakan salah satu komponen penting dalam menunjang kesinambungan usaha.

\section{METODE}

Magang praktek kerja dilaksanakan selama 4 bulan. Sebelum pelepasan mahasiswa kelokasi, mahasiswa terlebih dahulu dibekali melalui pembekalan dengan menjelaskan tujuan dari program MBKM ini. Adapun tahapan pelaksanaan MBKM di PT Sang Hyang Seri Cabang Sidrap yaitu :

1. Melakukan observasi lapangan. yaitu mengadakan pengamatan secara langsung di lokasi penelitian untuk mengetahui situasi dan kondisi yang berkaitan dengan objek penelitian. (Irwan et al., 2019)

2. Silaturahim bersama karyawan

3. Pemberian materi

4. Melakukan kegiatan-kegiatan yang dapat memberikan mahasiswa pengalamanpengalaman baru.

\section{HASIL DAN PEMBAHASAN}

Program MBKM ini juga melatih jiwa kepemimpinan mahasiswa. Kepemimpinan sebagai proses memberikan inspirasi kepada semua karyawan untuk bekerja sebaik-baiknya agar dapar mencapai hasil yang diharapkan. Kepemimpinan juga merupakan dimensi utama yang sangat menentukan kinerja organisasi.

Dimana esensi pokok kepemimpinan yaitu upaya mempengaruhi orang agar dapat lebih efektif, disebabkan dalam kepemimpinannya bisa berbeda tergantung karakter, karakteristik tugas dan siapa yang dipimpinnya. (Latif, Mustanir, et al., 2019)

Kepemimpinan juga merupakan seni atau tehnik, sekaligus ilmu dalam memberikan perintah atau anjuran, serta pengertian- pengertian agar dapat dipahami oleh orang-orang, dan supaya kekuasaan untuk mengajak, mempengaruhi, menggerakkan dan berjalan dengan baik dan supaya melakukan demi pencapaian tujuan pemimpin harus ada dalam suatu kelompok atau organisasi, dengan demikian keberadaan pemimpin bisa dapat dikenal oleh anggota atau pun masyarakat yang luas 
dalam kepemimpinannya nanti. (Irwan et al., 2019)

Kepemimpinan memiliki fungsi sebagai penggerak atau dinamisator dan koordinator dari sumber daya manusia, sumber daya alam, semua dana serta sarana yang disiapkan oleh sekumpulan manusia yang berorganisasi. (Mustanir et al., 2019)

Selain melatih kepemimpinan mahasiswa, mahasiswa mendapatkan pengalaman pengalaman lainnya selama magang di instansi seperti bekerja sama dengan mahasiswa peserta magang lainnya.

Kerja sama mahasiswa bisa dilihat dari kegiatan pada saat pemberian label.

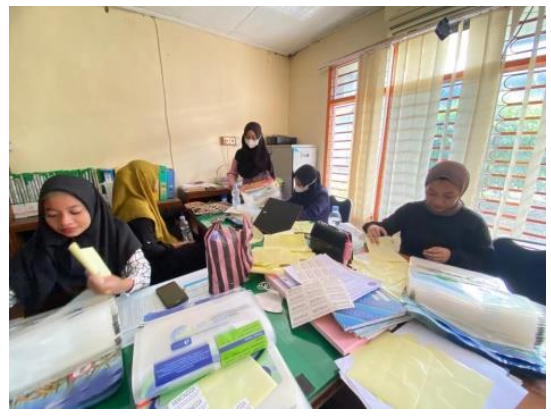

Gambar 1

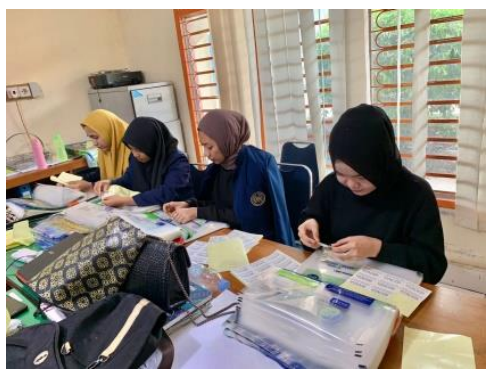

\section{Gambar 2}

Label adalah keterangan yang diberikan pada benih yang sudah dikemas setelah penerbitan sertifikat mutu benih atau keterangan mutu benih.
Kegiatan lain yang dilakukan yaitu mengumpulkan file Faktur penjualan. Faktur penjualan itu sendiri sebagai bukti fisik transaksi bisnis, dengan adanya faktur ini dapat menjadi dokumen untuk pelanggan maupun perusahaan.

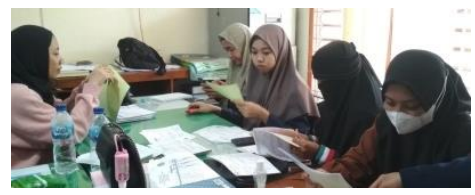

Gambar 3

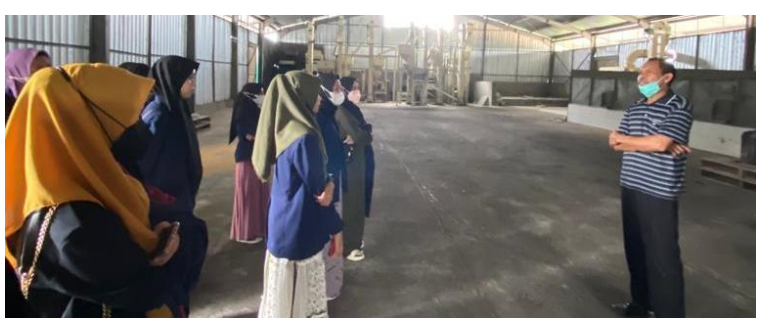

\section{Gambar 4}

Penyelesaian pekerjaan dengan semangat yang baik. Kinerja tidak hanya menyangkut ketaatan seorang pegawai pada perusahaan, tetapi juga menyangkut semangat dan kegairahan kerja. Setiap pegawai idealnya harus dapat bekerja dengan penuh tanggung jawab, bukan keterpaksaan atau karena takut mendapat sanksi.(Irwan et al., 2019)

Upaya pemerintah mewujudkan swasembada pangan perlu adanya dukungan sumber daya manusia, sarana (benih) prasarana, dan dukungan masyarakat. Benih salah satu komponen utama dalam mendukung keberhasilan budidaya tanaman pangan. Peranan kelompok tani sebagai unit produksi sangat penting dalam penyediaan benih padi sawah di daerah. Peran kelompok tani dalam hal ini sebagai partisipasi dalam mewujudkan swasembada pangan. 
Partisipasi masyarakat pada dasarnya merupakan kesediaan seseorang secara

ikhlas untuk membantu kegiatan pembangunan yang berlangsung di daerahnya, karena partisipasi yang dilakukan dengan ikhlas (sukarela) akan membuat masyarakat merasa senang dengan turut menjadi bagian dari kegiatan tersebut. (Irwan et al., 2021). Partisipasi dalam/melalui kontak dengan pihak lain sebagai awal perubahan sosial. (Sapri et al., 2019)

Partisipasi masyarakat selalu mengikutsertakan masyarakat (keikutsertaan dalam melakukan kegiatan pengidentifikasian problem dan potensipotensi yang ada didalam masyarakatnya) (Latif, Mustanir, et al., 2019) dengan mengakomodasikan kepentingan mereka dalam proses penyusunan rencana pembangunan. (Mustanir \& Yasin, 2018). Lingkungan berpengaruh pada partisipasi, tergantung dari lamanya orang tersebut dalam lingkungan itu. (Uceng et al., 2019)

Partisipasi anggota masyarakat merupakan keterlibatan anggota masyarakat dalam pembangunan, meliputi kegiatan dalam perencanaan dan pelaksanaan (implementasi) program/proyek pembangunan yang dikerjakan di dalam masyarakat.(Mustanir \& Abadi, 2017)

Masyarakat akan lebih percaya proyek atau program pembangunan jika merasa dilibatkan dalam proses persiapan dan perencanannya. (Mustanir et al., 2018) Dengan adanya peran partisipasi masyarakat maka hasil dari pembangunan yang dilakukan nantinya diharapkan dapat sesuai dengan keinginan dan kebutuhan dari masyarakat. (Mustanir et al., 2020)

Partisipasi memiliki maksud dasar menjadi instrumen yang memberikan peluang yang besar bagi masyarakat untuk dapat berkembang sesuai dengan potensinya. (Latif, Rusdi, et al., 2019). Partisipasi masyarakat merupakan perwujudan dari kesadaran dan kepedulian serta tanggung jawab masyarakat memperbaiki mutu hidup mereka. (Irwan et al., 2019).

Dengan berbagai kegiatan yang dilakukan, mahasiswa sebagai peserta Magang Praktek Kerja mendapatkan banyak pengalaman baru disini. Selain hardskill, softskill pun didapatkan.

\section{KESIMPULAN}

Kompetensi mahasiswa meningkat dengan banyaknya pengalaman yang didapatkan selama bermagang di instansi. Selain Hardskill yang didapatkan seperti keterampilan, softskill juga didapatkan seperti etika bekerja. Dengan adanya partisipasi masyarakat akan mendukung pelaksanaan program pembangunan salah satunya yaitu kelompok tani yang tentunya bisa mendukung terwujudnya swasembada.

\section{DAFTAR PUSTAKA}

Irwan, Latif, A., \& Mustanir, A. (2021). PENDEKATAN PARTISIPATIF DALAM PERENCANAAN PEMBANGUNAN DI KABUPATEN SIDENRENG RAPPANG. Jurnal Kajian, Penelitian Dan Pengembangan 
Pendidikan, 9(2), 137-151.

Irwan, Latif, A., Sofyan, Mustanir, A., \& Fatimah. (2019). Gaya Kepemimpinan, Kinerja Aparatur Sipil Negara dan Partisipasi Masyarakat Terhadap Pembangunan di Kecamatan Kulo Kabupaten Sidenreng Rappang. Jurnal Moderat, 5(1), 32-43. https://jurnal.unigal.ac.id/index.php/mo derat

Latif, A., Mustanir, A., \& Irwan, I. (2019). Pengaruh Kepemimpinan Terhadap Partisipasi Masyarakat Pada Perencanaan Pembangunan. JAKPP (Jurnal Analisis Kebijakan \& Pelayanan Publik), 5(2), 144-164. https://doi.org/10.31947/jakpp.v1i2.797 7

Latif, A., Rusdi, M., Mustanir, A., \& Sutrisno, M. (2019). Partisipasi Masyarakat Dalam Pembangunan Infrastruktur Di Desa Timoreng Panua Kecamatan Panca Rijang Kabupaten Sidenreng Rappang Dosen Ilmu Pemerintahan Stisip Muhammadiyah Rappang Dosen Ilmu Administrasi Negara Stisip Muhammadiyah Rappang 5). Jurnal MODERAT, 5(1), 1-15. https://jurnal.unigal.ac.id/index.php/mo derat/article/view/1898

Muniarty, P., \& Saputri, D. (2021). PENINGKATAN KOMPETENSI MAHASISWA MELALUI PEMBEKALAN KULIAH KERJA NYATA TEMATIK. 2(1), 1-12.

Mustanir, A., \& Abadi, P. (2017). Partisipasi Masyarakat Dalam Musyawarah Rencana Pembangunan Di Kelurahan Kanyuara Kecamatan Watang Sidenreng Kabupaten Sidenreng Rappang. Jurnal Politik Profetik, 5(2), 247-261. http://journal.uinalauddin.ac.id/index.php/jpp/article/vie
wFile/4347/3986\%0Ahttp://journal.uinalauddin.ac.id/index.php/jpp/issue/view 1636

Mustanir, A., Fitriani, S., Adri, K. Nurnawati, A. A., \& Goso, G. (2020). Sinergitas Peran Pemerintah Desa dan Partisipasi Masyarakat Terhadap Perencanaan Pembangunan di Kabupaten Sidenreng Rappang (The Synergy of Village Government's Role and Community Participation in the Process of Development Planning in Sidenreng Rappang D. Journal of Government Science (GovSci), 2020(2), 84-108.

Mustanir, A., Samad, Z., Ibrahim, M., \& Juniati. (2019). KEPEMIMPINAN LURAH TERHADAP PEMBERDAYAAN MASYARAKAT DI KELURAHAN LAUTANG BENTENG KABUPATEN SIDENRENG RAPPANG. Journal of Social Politics and Governance, 1(2), 20-39.

Mustanir, A., Sellang, K., Ali, A., Madaling, \& Mutmainna. (2018). Peranan Aparatur Pemerintahan Desa dan Partisipasi Masyarakat Dalam Musyawarah Perencanaan Pembangunan di Desa Tonrongnge Kecamatan Baranti Kabupaten Sidenreng Rappang. Jurnal Ilmiah Clean Government, 2(Desember), 6784.

http://lonsuit.unismuhluwuk.ac.id/index .php/clean/article/view/213

Mustanir, A., \& Yasin, A. (2018). Community Participation in Transect on Development Planning. Jurnal Ilmiah Ilmu Administrasi Publik, 8(2), 137. https://doi.org/10.26858/jiap.v8i2.7994

Sapri, Mustanir, A., Ibrahim, M., Astinah 
Adnan, A., \& Wirfandi. (2019).

Peranan Camat dan Partisipasi Masyarakat Dalam Musyawarah

Perencanaan Pembangunan Di

Kecamatan Enrekang Kabupaten Enrekang. MODERAT: Jurnal Ilmiah

Ilmu Pemerintahan, 5(2), 33-48. https://jurnal.unigal.ac.id/index.php/mo derat/article/view/2127

Uceng, A., Ali, A., Mustanir, A., \& Nirmawati. (2019). Analisis Tingkat Partisipasi Masyarakat Terhadap Pembangunan Sumber Daya Manusia Di Desa Cemba Kecamatan Enrekang Kabupaten Enrekang. MJurnal Moderat, 5(2), 1-17. 